\title{
Peculiarities of development the world coal industry in the process of active decarbonization in the world's economy
}

\author{
Aleksandr Prosekov, and Artem Rada* \\ Kemerovo State University, 650000 Krasnaja ulica 6, Kemerovo, Russia
}

\begin{abstract}
Launch of the process of decarbonization of the economy and ratification of the Paris Climate Agreements in 2015-2016 puts the world's coal industry in a difficult position. The purpose of the study is to identify the features of the development of the global coal industry, including regional ones, in anticipation of the active decarbonization of the world economy. For this, a quantitative analysis of the dynamics and structure of world coal production in 2010-2020 was carried out. As a result, it was revealed that the impact of the 2020 crisis did not become decisive for production. It can be compared to a price shock or the start of implementation of the Paris Climate Agreements. Some of the dynamics of the global coal production indicator is characterized by a weak declining trend (about minus $0.05 \%$ per year), although this indicator is generally unstable. The dynamics of coal production is characterized by the absence of an internal trend of self-development; autocorrelation is observed. The dynamics of coal production reacts to external shocks, while the regional differentiation of this indicator is growing. For 2010-2020 the share of North America and Europe fell to 13\%, and the Asia-Pacific region increased to $75 \%$. Most developed countries are striving to reduce the production and consumption of coal (in the USA, Germany, Poland - by 25-50\%), but many developing countries (India, Indonesia, Vietnam, Mongolia) are rapidly increasing production (by $30-70 \%$ ). This is due to the possibility of exporting and using relatively cheap local fuel for economic development. Therefore, in the medium term, global coal production will remain stable with growing regional differentiation.
\end{abstract}

\section{Introduction}

The world economy is entering the stage of decarbonization and the formation of a lowcarbon development model with zero or minimum balance of emissions of greenhouse gases such as carbon dioxide. One of the main directions of decarbonization is to minimize the use of fossil fuels, including natural gas, oil, and, in particular, coal. As you know, their combustion leads to the emission of a significant amount of greenhouse gases, including carbon dioxide $\left(\mathrm{CO}_{2}\right)$, methane $\left(\mathrm{CH}_{4}\right)$ and dinitrogen oxide $(\mathrm{N} 2 \mathrm{O})$ [1, 2]. Significant

\footnotetext{
*Corresponding author: rada.ao@kemsu.ru
} 
amounts of methane are also released during mining operations in coal seams and other types of fossil fuel deposits.

Compared to other fossil fuels, various coals (bituminous, semi-bituminous, lignite) have twice the default carbon dioxide emission factor. Therefore, reducing the production and consumption of coal compared to other fuels is a priority for many countries. It is the coal industry that is considered as the entity responsible for a significant share of greenhouse gas emissions [3].

Consequently, the prospects for the global coal industry in the next 30-40 years, when most countries move to low-carbon or carbon-free economies, look very difficult. A number of research questions arise about the state and prospects of the coal industry:

RQ1: what are the features of the development of the global coal industry in the nearest retrospective, how much is it possible to change the current trends?

RQ2: what are the regional characteristics of coal production and consumption, and how can they affect the decarbonization processes?

Analysis of scientific literature shows that the specifics of the development of the coal industry in the last decade and its prospects in the 2030-2050 not yet sufficiently researched, especially in the context of the decarbonization of the economy. However, quite a lot of scientific publications analyze the place of the coal industry and coal energy in the process of greenhouse gas emissions.

In a study by A. Fiehn et al. on the basis of materials from the coal enterprises of Upper Silesia (Poland), measurements of emissions of the three main greenhouse gases were carried out using ground and aviation measurements. In particular, "emissions of $\mathrm{CO}_{2}$ were determined to be $1.21 \pm 0.75$ and $1.12 \pm 0.38 \mathrm{t} \mathrm{s}-1$ " [4]. This is a significant amount of emissions. An even more complex issue is methane emissions, which have a much stronger greenhouse effect. At the same time, methane emissions from coal mining are significantly higher than those from the extraction of even oil and natural gas.

Reassessment of methane emissions from fossil fuel extraction by S. Schwietzke et al. based on isotope signature data, showed that emissions from the extraction of all fossil fuels, as well as natural methane emissions, were $60-110 \%$ higher than those estimates given in the early 2010s. The energy potential of methane released during coal mining is comparable to the calorific value of the reserves themselves [5]. This, in particular, indicates the feasibility of capturing and using methane as a combustible gas.

It should also be borne in mind that inactive coal mines and open-pit mines continue to emit greenhouse gases. N. Kholod et al. it has been demonstrated that global methane emissions can raise even with a decrease in coal production, as methane continues to be released from the mine workings of closed coal mines. In addition, the deepening of the horizons of underground operations as more accessible reserves are developed also leads to an increase in specific methane emissions per ton of coal [6]. In the shafts of coal mines, according to J. Swolkien, the concentration of methane ranges from 0.05 to $0.4 \%$, as a result, from one shaft per minute, 18 to 75 cubic meters of methane are released into the atmosphere [7].

Reviewed by L. Liu et al. states that greenhouse gas emissions should be considered and estimated at all stages of the life cycle from mining to waste disposal. In particular, a significant part of emissions falls on crushing and grinding of coal, which releases methane reserves hidden deep in the pores [8]. The influence of coal combustion on greenhouse gas emissions has also been studied in sufficient detail.

As noted above, when coal is burned, more greenhouse gases are emitted compared to other types of fossil fuels (liquid petroleum products and natural gas) [3]. When one unit of energy, for example, 1 mega joule, is produced, almost twice as much carbon dioxide is released from coal than when natural gas is burned. This is due to the different calorific 
value (calorific value) of gas and coal, and different content of greenhouse gases, including methane [9].

As noted in the review by M. Whitaker et al., existing estimates of greenhouse gas emissions from electricity generation from coal-fired power plants are somewhat different. This is due to the quality of coal (in terms of moisture content, ash content, size) and the peculiarities of the combustion technology used (Subcritical, Fluidized Bed, etc.) [10]. Nevertheless, they are in any case quite high and coal generation is responsible for a significant share of global greenhouse gas emissions.

The analysis of carbon emissions in China's coal supply and use chains was carried out by G. Luo et al. The study considered four processes: coal mining, coal processing and beneficiation, transportation, consumption (combustion). As a result, it was found that more than $80 \%$ of greenhouse gas emissions come from coal combustion (although this parameter may vary depending on the combustion technology) [11]. Therefore, for example, in Germany, where $35 \%$ of electricity is produced by burning coal, it is planned to completely stop using coal and brown coal by 2038 [12].

These factors negatively affect the prospects for the coal industry. It is logical to expect a significant reduction in coal production and consumption. In addition, the consumption of coal, like other fossil fuels, significantly decreased in 2020 due to the spread of COVID-19, the introduction of quarantines and lockdowns in most countries of the world.

According to P. Parra, C. Hauenstein, P.-Y. Oei, "false hopes for a" V "or" U "shape of the coal demand curve (assuming a recovery) will have to be replaced by an" L "or" $\backslash$ "shape demand outlook" [13]. At the same time, most researchers believe that in developed countries, coal mining will practically stop in the 2040-2060. At the same time, many developing countries will not be able to abandon the use of coal and its consumption may increase [14].

Taking into account all of the above, the purpose of the study is to identify the features of the development of the global coal industry, including regional ones, in anticipation of the active decarbonization of the world economy

\section{Research methodologies}

The study is based on a quantitative analysis of data characterizing the development trends of the coal industry in the world and individual regions in the 2010-2020s. This data is published by the International Energy Agency, The U.S. Energy Information Administration, BP, Enerdata. They relate to the volumes of coal production and consumption, regional distribution of reserves, production and consumption.

To process the data, standard statistical and econometric methods were used to study dynamics, structural breaks, including descriptive statistics, regression analysis, the Durbin-Watson test for assessing autocorrelation, the Goldfield-Quantum test for heteroscedasticity, and structural change indices. The calculations were performed at the Center for Shared Use of Scientific Equipment at Kemerovo State University (Kemerovo, Russia).

\section{Research results}

Table 1 shows the dynamics of coal production in the world in the period 2010-2020 and the main indicators of the corresponding data series. The data in Table 1 show that the total coal production in 2020 compared to 2010 remained practically unchanged (a decrease of less than $1 \%$ or 41 million tons). However, within the period, the fluctuations were quite 
strong. So, for 2013-2016 the overall decline in production was almost 10\%. In 2011-2012 there was a significant increase in coal production worldwide, as in 2017 global coal production remained stable, but fell sharply in 2020 (by almost 6\%).

Table 1. Dynamics of coal production in the world in 2010-2020.

\begin{tabular}{|c|c|c|}
\hline & Production volume, million tons & Growth rate, percent \\
\hline 2010 & 7479 & no date \\
\hline 2011 & 7975 & 6.63 \\
\hline 2012 & 8203 & 2.86 \\
\hline 2013 & 8270 & 0.82 \\
\hline 2014 & 8195 & $(0.91)$ \\
\hline 2015 & 7917 & $(3.40)$ \\
\hline 2016 & 7402 & $(6.50)$ \\
\hline 2017 & 7666 & 3.57 \\
\hline 2018 & 7789 & 0.30 \\
\hline 2019 & 7906 & 1.50 \\
\hline 2020 & 7438 & $(5.92)$ \\
\hline $\begin{array}{l}\text { Total increase (decrease), } 2019 \text { to } \\
2010\end{array}$ & 427 & 5.71 \\
\hline $\begin{array}{l}\text { Total growth (decline } 2020 \text { to } \\
\text { 2010) }\end{array}$ & -41 & $(0.55)$ \\
\hline
\end{tabular}

To analyze a number of dynamics characterizing global coal production, two periods were considered: from 2010 to 2019 and from 2010 to 2020.This is explained by the fact that the impact of the external shock - the COVID-19 pandemic and the ensuing macroeconomic recession, requires a differentiated analysis. When examining the first period, it is found that in 2019 compared to the baseline 2020, coal production increased by 427 million tons, or 6\%. The average chronological interval series was 7901 million tons. The average growth rate was $0.62 \%$, it was small but stable.

A number of dynamics were tested for the presence of first-order autocorrelation by the Durbin-Watson $(D W)$ test. The actual value of the criterion is 0.98 , therefore, autocorrelation is present, although not very high (the absence of autocorrelation corresponds to the interval from $d l=1.08$ to $d 2=1.36$ ). At the same time, heteroscedasticity is absent in the series of dynamics, since the F-statistic in the GoldfieldQuandt test was 7.38, while the critical value is 10.10 .

Consequently, the dynamics of coal production in the world already in the period 20102019 experienced the influence of external shocks. It cannot be sufficiently reliably estimated and predicted only on the basis of the trend equation built on the basis of a number of observation periods. Therefore, any version of the trend equation (linear, polynomial, logarithmic, etc.) turns out to be statistically insignificant. Apparently, the dynamics of coal production was shaped by such factors as changes in world prices, fluctuations in temperature regimes in different years and measures to limit carbon emissions. In general, production tended to be around 8000 million tons per year. 
In 2020, as noted above, global coal production declined significantly. However, this decline is not unprecedented. In 2016 compared to 2015, the decline in global coal production was stronger than in 2020 compared to 2019 (both in absolute and relative terms). Consequently, the spread of COVID-19, the introduction of lockdowns and various restrictions have certainly impacted the global coal industry. But this is not the most powerful factor affecting coal mining in the world.

As you know, in 2020, small and medium-sized businesses, the hospitality industry, passenger transportation, and technically complex industries with complex global supply chains have suffered the most. The fuel and energy industries, which provide vital human needs, have reduced production volumes to a lesser extent. In other words, a coronavirus shock for the coal industry is comparable in impact to a price shock or to decisions to reduce greenhouse gas emissions. Therefore, 2020 can be considered in conjunction with the previous period, the decline in production this year was not extremely high.

Analysis of a number of dynamics reflecting data for 2010-2020 leads to the following results. As noted earlier, in general, coal production declined slightly over this period. The average decline in coal production was $0.05 \%$ per year (or about 4 million tons). The general trend is rather decreasing. The average chronological series of dynamics is 7878 million tons, which is slightly less than in the period 2010-2019.

The actual value of the Durbin-Watson $D W$ test was 1.13. In the absence of autocorrelation, the condition $d 1<D W$ and $d 2<D W<4-d 2$ must be satisfied. Since, as noted above, at the $5 \%$ significance level $\mathrm{d} 1=1.08 ; \mathrm{d} 2=1.36$, then autocorrelation takes place. This makes it difficult to construct trend equations that explain the dynamics of global coal production by internal laws. It is logical to formulate a hypothesis that its value is influenced by exogenous influences (market, institutional, and others).

Checking the presence of heteroscedasticity showed that the F-statistic in the Goldfield-Quandt test was 1.47. At 3.5 degrees of freedom, the critical value is 7.71; therefore, there is no heteroscedasticity. However, the construction of the regression equation is difficult. We tested hypotheses about several types of constraint equations, including linear, polynomial, hyperbolic, exponential, logarithmic, but it is impossible to correctly describe the dynamics of world coal production with their help. Consequently, to understand the ongoing processes, it is necessary to analyze the structure of coal mining and external shocks that took place in the period under study.

\section{The discussion of the results}

A better understanding of why global coal production has changed can be gained by looking at the price dynamics of coal markets, institutional constraints for coal energy, and structural shifts in global production by region. Firstly, during the extraction of coal, a mining rent is formed, which, with an increase in the general level of prices, makes it necessary to start mining in mines and open-pit mines with comparatively worse mining and geological conditions. Second, the governments of developed countries, committed to the idea of decarbonizing the economy, can make decisions that force them to cut production.

Third, the dynamics of coal production is highly differentiated by region. While Germany seeks to reduce coal generation as much as possible, many developing countries view coal as a promising resource for the industrialization of the economy. Table 2 shows the structure of coal production in the world by macro regions of the world, table 3 - the contribution of different countries to world production.

The data in Table 2 show that the structure of global coal production has seriously changed, although 11 years is historically a fairly short period for a change in stable interregional proportions. The share of Total North America from 2010 to 2019 decreased 
1.7 times, and from 2010 to 2020 - more than twice. The share of Total Europe also decreased 1.5 times and 1.7 times, respectively.

Thus, in the most developed countries of the world, only about $13 \%$ of coal is mined, which is incomparable with their contribution to world GDP. Note also that in 2020 the decline in the share of Europe and North America in global coal production accelerated. This is explainable by the highest, in comparison with developing countries and countries of the Commonwealth of Independent States, the rigidity and duration of administrative restrictions on economic activity.

Table 2. Structure of world coal production by region, percent.

\begin{tabular}{|c|c|c|c|c|c|c|}
\hline & $\mathbf{2 0 1 0}$ & $\mathbf{2 0 1 5}$ & $\mathbf{2 0 1 9}$ & $\mathbf{2 0 2 0}$ & $\begin{array}{c}\text { Change 2019 } \\
\text { to 2010 }\end{array}$ & $\begin{array}{c}\text { Change 2020 } \\
\text { to 2010 }\end{array}$ \\
\hline Total North America & 14.3 & 11.2 & 8.6 & 6.9 & $(5.7)$ & $(7.4)$ \\
\hline $\begin{array}{c}\text { Total South \& Central } \\
\text { America }\end{array}$ & 1.1 & 1.2 & 1.1 & 0.8 & 0.0 & $(0.4)$ \\
\hline Total Europe & 10.2 & 8.6 & 7.0 & 6.2 & $(3.2)$ & $(4.0)$ \\
\hline $\begin{array}{c}\text { Total Commonwealth of } \\
\text { Independent States }\end{array}$ & 5.9 & 6.1 & 7.0 & 6.8 & 1.1 & 0.9 \\
\hline Total Middle East & 0.0 & 0.0 & 0.0 & 0.0 & 0.0 & 0.0 \\
\hline Total Africa & 3.5 & 3.3 & 3.5 & 3.5 & 0.0 & 0.0 \\
\hline Total Asia Pacific & 65.0 & 69.5 & 72.8 & 75.9 & 7.8 & 11.0 \\
\hline Total World & 100.0 & 100.0 & 100.0 & 100.0 & 0.0 & 0.0 \\
\hline
\end{tabular}

The share of the countries of the Commonwealth of Independent States, primarily Russia and Kazakhstan, in world coal production was unstable. In 2019, it slightly increased, mainly due to the extraction of coal for export supplies. However, in 2020 there was a decrease due to a drop in demand in the European market.

The share of the Asia-Pacific region grew steadily and rapidly. In 2020, it accounted for more than $75 \%$ of world production (compared to $65 \%$ in 2010). It is home to the world's largest coal producer, China, which accounts for about $50 \%$ of world production. However, this country has been holding back the growth of the coal industry in recent years. The main contribution to the increase in coal production comes from countries such as India and especially Indonesia (table 3).

The growth in coal production in China can be considered moderate and fairly balanced (about $18 \%$ over 10 years), although due to the reduction of the coal industry in many countries, the share of this country has exceeded 50\%. Very high growth rates were observed in the coal industry in India and Russia (about 33\%), as well as Indonesia (over 70\%). This to some extent compensated for the decline in production in Europe, Canada and the United States. Production in Australia, South Africa and Kazakhstan remained stable.

Thus, a number of countries around the world are not focused on the trajectory of decarbonization of the world economy due, first of all, to minimizing coal production. Rapid population growth (in India and Indonesia), the opportunity and need for export earnings have led to the rapid development of the Indonesian, Indian and Russian coal industry. Objective circumstances exclude the possibility of a significant reduction in production volumes in the short term. Substitution of sources of foreign exchange earnings for the purchase of the necessary imported products is extremely problematic. In addition, 
the most affordable fuel in a situation of population growth and urbanization can be precisely coal, the reserves of which are in a large number of countries around the world. Most often, gas and oil have to be purchased using foreign currency.

Table 3. Structure of world coal production by region, percent.

\begin{tabular}{|c|c|c|c|c|c|c|c|c|c|c|}
\hline & \multicolumn{2}{|c|}{2010} & \multicolumn{2}{|c|}{2015} & \multicolumn{2}{|c|}{2019} & \multicolumn{2}{|c|}{2020} & \multirow{2}{*}{$\begin{array}{l}\text { Growth } \\
\text { rate, \% }\end{array}$} & \multirow{2}{*}{$\begin{array}{c}\text { Change } \\
\text { in } \\
\text { share, } \\
\%\end{array}$} \\
\hline & $\underset{t}{\operatorname{mln}}$ & $\%$ & $\underset{t}{\mathrm{mln}}$ & $\%$ & $\underset{t}{\mathrm{mln}}$ & $\%$ & $\underset{t}{\mathrm{mln}}$ & $\%$ & & \\
\hline China & 3316 & 44.4 & 3653 & 46.5 & 3692 & 45.4 & 3902 & 50.4 & 117.7 & 6.0 \\
\hline India & 570 & 7.6 & 683 & 8.7 & 745 & 9.2 & 757 & 9.8 & 132.8 & 2.1 \\
\hline USA & 996 & 13.4 & 841 & 10.7 & 640 & 7.9 & 485 & 6.3 & 48.7 & $(7.1)$ \\
\hline Australia & 436 & 5.8 & 512 & 6.5 & 500 & 6.1 & 477 & 6.2 & 109.4 & 0.3 \\
\hline Indonesia & 325 & 4.4 & 455 & 5.8 & 585 & 7.2 & 563 & 7.3 & 173.2 & 2.9 \\
\hline Russia & 300 & 4.0 & 353 & 4.5 & 425 & 5.2 & 400 & 5.2 & 133.3 & 1.1 \\
\hline $\begin{array}{l}\text { South } \\
\text { Africa }\end{array}$ & 255 & 3.4 & 255 & 3.2 & 264 & 3.2 & 248 & 3.2 & 97.3 & $(0.2)$ \\
\hline Germany & 184 & 2.5 & 185 & 2.4 & 132 & 1.6 & 107 & 1.4 & 58.2 & -1.1 \\
\hline Poland & 133 & 1.8 & 136 & 1.7 & 112 & 1.4 & 101 & 1.3 & 75.9 & $(0.5)$ \\
\hline Kazakhstan & 111 & 1.5 & 107 & 1.4 & 117 & 1.4 & 113 & 1.5 & 101.8 & 0.0 \\
\hline $\begin{array}{l}\text { Total for } \\
\text { the top } 10 \\
\text { countries }\end{array}$ & 6626 & 88.8 & 7180 & 91.3 & 7212 & 88.7 & 7153 & 92.4 & 108.0 & 3.6 \\
\hline
\end{tabular}

Consequently, the relatively stable level of coal production was formed on the basis of a combination of sharp declines in developed countries and similar growth in developing countries. Poland, Germany and the United States reduced their coal production most radically (a decrease of 25-50\%), but the actions of a number of other states minimized the significance of this fact for the decarbonization of the global economy. Along with Indonesia, India and Russia, it is necessary to note the rapid growth in coal production in a number of countries that are not yet among the 10 largest world producers. So, in Turkey, production in 2020 compared to 2019 increased by 13.7 million tons, or about $19 \%$. In Mongolia, similar indicators amounted to 17.9 million tons and about $71 \%$, respectively.

Outside developed countries with diversified economies, exports, significant financial and investment potential, the level of concern about the carbon agenda is significantly lower. Their governments and populations are more often concerned with the challenges of today, such as jobs, access to fuel and export opportunities, rather than global warming in the future. Therefore, there is no reason to predict a significant drop in global coal production in the medium term; it will sharply differentiate across the countries of the world.

For many developing countries, it is important to consume coal as the most affordable fuel, but at the same time, the dynamics of the coal industry is determined by exports. On the one hand, global coal production does not correlate with coal prices, since domestic supplies are of great importance. Pearson's pairwise correlation coefficient between global 
coal production and the Northwest Europe marker price is 0.3202 , with a critical value for 9 degrees of freedom at a $5 \%$ significance level of about 0.6021 .

But in some countries - coal exporters, the change in the price situation is inversely proportional to the volume of production. The fall in world prices is forcing higher volumes to be offered to the market in order to compensate for the loss of foreign exchange earnings in absolute terms. A statistically significant negative relationship between prices and coal production is observed in Australia (pair correlation coefficient minus 0.7152), India (minus 0.6396) and Indonesia (minus 0.6062). With this dependence on exports, it is possible to predict the preservation of significant volumes of production in these countries. In Russia and Kazakhstan, the correlation is also negative, but below the level of statistical significance.

\section{Conclusions}

In the period 2010-2020 the global coal industry developed in difficult conditions. These include difficulties in the global coal market and price shocks, restrictions on greenhouse gas emissions and the policy of transition to a low-carbon economy, as well as the economic crisis in 2020 caused by the introduction of lockdowns and quarantine measures. However, in general, the dynamics of world coal production remained fairly stable. There was a significant increase in 2011-2012, serious decreases in 2015-2016, 2020. However, in 2010-2019 production growth was observed at the level of about $0.62 \%$ per year. When included in the analysis of data for 2020, there is a slight decrease (about $0.05 \%$ per year) with an average chronological value of about 7.9 billion tons.

The events of 2020 influenced the decline in coal production, but the consequences cannot be considered catastrophic. The coal industry, which meets the primary needs of the economy and people, has been more resilient in a crisis. The drop in production was lower than, for example, in 2016. The impact of the coronavirus crisis is comparable to a large drop in prices or the ratification of the Paris Climate Agreements.

When analyzing the series of dynamics for 2010-2019 and 2010-2020 it is found that there is no pronounced internal trend, autocorrelation is observed. Consequently, as expected, the dynamics of global coal production was determined by external shocks, and not by internal factors of self-development. Interregional structural shifts have become the most characteristic feature of the development of the coal industry.

The share of the most developed countries in Europe and North America in coal mining decreased to $13 \%$ (mainly due to a decrease in production in the USA, Germany, and Poland by $25-50 \%)$. At the same time, the share of the Asia-Pacific region increased to $65 \%$, and China's contribution exceeded $50 \%$ of world production. Moreover, the 2020 coronavirus crisis accelerated this structural shift due to the greater severity and duration of restrictions in developed countries. If the level of production in China, Australia, and Kazakhstan can be considered stable, then a number of states have significantly increased it.

In Russia, India, and especially in Indonesia, as well as in Mongolia and Turkey, production in 2010-2020 increased by $30-70 \%$. The most important factors in this were lucrative coal exports in the Asia-Pacific region, as well as population growth in several countries and the need for reasonably cheap local energy sources. Countries such as Indonesia or India or Vietnam have few real opportunities to stop using and exporting coal. The development of the local economy requires fuel, which, for financial reasons, is difficult or impossible to purchase with foreign currency. In addition, coal exports make a significant contribution to the economies of these countries.

Therefore, in the future, we should expect further growth in coal production in most countries of the Asia-Pacific region, in contrast to the trends observed in Europe and North 
America. The level of economic development of many countries objectively forces them to give priority attention to the current tasks of economic growth, rather than building a green economy, which requires colossal costs of the state and companies. Thus, with a further shift in interregional proportions, global coal production in the medium term will be close to the current level prevailing in the period 2010-2020.

Comparison of three variants of the strategy of socio-economic development of the Kemerovo region - Kuzbass (2008, 2018, and 2020) showed that the absolute increase exceeded 6 times, and the relative frequency of occurrence increased by $40.2 \%$ and $49.3 \%$, respectively. Development strategies for the region are becoming increasingly committed to the principles and goals of sustainable development, although uneven growth has been observed across different goals. For example, in the 2018 version, the incidence of descriptors associated with responsible production and consumption, health, and education has sharply increased, which is due to the objective problems of the Kemerovo region Kuzbass.

Another factor influencing the change in the occurrence of different categories of descriptors is the use of different theoretical and methodological foundations of strategizing (or ignoring them). The 2020 version, developed by professional strategists, excluded from consideration tactical issues and current problems that are not the object of strategic management. Therefore, the number of descriptors related to education and healthcare has decreased to a reasonable level (where some of the problems in 2020 compared to 2018 have already been resolved). The frequency of mentioning such important goals as clean water, infrastructure development, responsible production and consumption, and the fight against climate change has increased significantly.

\section{Acknowledgment}

The work was carried out at the Centre for Shared Use of Scientific Equipment of the Kemerovo State University, created with the funds of the federal target program "Research and Development in Priority Areas of Development of the Scientific and Technological Complex of Russia for 2014-2020" (The competition was organized by the Ministry of Science and Higher Education of the Russian Federation).

\section{References}

1. J. Lelieveld, K. Klingmüller, A. Pozzer, R. T. Burnett, A. Haines, V. Ramanathan, Proceedings of the National Academy of Sciences, 116, 15 (2019)

2. W. Lamb, T. Wiedmann, J. Pongratz R. Andrew, M. Crippa, J. Olivier, Environmental Research Letters, 16, 7 (2021)

3. J. Linn, E. Mastrangelo, D. Burtraw, Journal of the Association of Environmental and Resource Economists, 1, 1/2 (2014)

4. A. Fiehn, J. Kostinek, M. Eckl, T. Klausner, M. Gałkowski, Atmospheric Chemistry and Physics, 20, 21 (2020)

5. S. Schwietzke, O. Sherwood, L. Bruhwiler, J. Miller, G. Etiope, Nature, 538 (2016)

6. N. Kholod, M. Evans, R. Pilcher, V. Roshchanka, F. Ruiz, M. Coté, R. Collings, Journal of Cleaner Production, 256 (2020)

7. J. Swolkień, International Journal of Greenhouse Gas Control, 94 (2020)

8. L. Liu, H. Ji, X. Lü, T. Wang, S. Zhi, F. Pei, D. Quan, International Journal of Minerals, Metallurgy and Materials, 28 (2021) 
9. S. Paraschiv, L. Paraschiv, Energy Reports, 6, 8 (2020)

10. M. Whitaker, G. Heath, P. O’Donoughue, M. Vorum, Journal of Industrial Ecology, 16 (2012)

11. G. Luo, J. Zhang, Y. Rao, X. Zhu, Y. Guo, Energies, 10, 11 (2017)

12. S. Ladage, M. Blumenberg, D. Franke, A. Bahr, R. Lutz, S. Schmidt, Scientific Reports, 11 (2021)

13. P. Parra, C. Hauenstein, P.-Y. Oei, Applied Energy, 228 (2021)

14. D. Welsby, J. Price, S. Pye, P. Ekins, Nature, 597 (2021) 